This is the pre-peer reviewed version of the following article: María Virginia Candal, Itxaso Calafel, Nora Aranburu, Mercedes Fernández, Gonzalo Gerrica-Echevarria, Antxon Santamaría, Alejandro J. Müller, Thermo-rheological effects on successful 3D printing of biodegradable polyesters, Additive Manufacturing 36 : (2020) // Article ID 101408, which has been published in final form at https://doi.org/10.1016/j.addma.2020.101408. (c) 2020 Elsevier. This article may be used for non-commercial purposes in accordance with Elsevier Terms and Conditions for Use of Self-Archived Versions

\title{
Thermo-rheological effects on succesful 3D printing of biodegradable polyesters
}

\author{
María Virginia Candal, ${ }^{\mathrm{a}, \mathrm{b}^{*}}$ Itxaso Calafel $^{\mathrm{b}}$, Nora Aranburu ${ }^{\mathrm{b}}$, Mercedes Fernández $^{\mathrm{b}}$, \\ Gonzalo Gerrica-Echevarria $^{\mathrm{b}}$, Antxon Santamaría ${ }^{\mathrm{b}^{*}}$ and Alejandro J. Müller ${ }^{\mathrm{b}, \mathrm{c}^{*}}$ \\ ${ }^{a}$ Universidad Simón Bolívar, Departamento de Mecánica, Grupo de Polímeros, Apartado \\ 89000, Caracas 1080-A, Venezuela \\ ${ }^{\mathrm{b}}$ POLYMAT and Polymer Science and Technology Department, Faculty of Chemistry, \\ University of the Basque Country UPV/EHU, Paseo Manuel de Lardizábal, 3, 20018 \\ Donostia-San Sebastián, Spain. \\ ${ }^{\mathrm{c}}$ IKERBASQUE, Basque Foundation for Science, Bilbao, Spain
}

*Corresponding authors: mariavirginia.candalp@ehu.es, antxon.santamaria@ehu.es, alejandrojesus.muller@ehu.es 


\begin{abstract}
Biodegradable polybutylene succinate (PBS) and poly (butylene succinate-ranadipate) (PBSA) were characterized to find the thermo-rheological bases for 3D printing by Fused Filament Fabrication (FFF). In dynamic viscoelastic measurements, the samples fulfilled time-temperature superposition and Cox Merz rule. The viscosity results were linked to the excellent filaments obtained and the observed good flow in the printer nozzle. Using specific tearing experiments, outstanding welding of the printed layers was obtained. Results were discussed considering the values of the entanglements density obtained by SAOS measurements. The main difference between both polymers was observed in the final production of $3 \mathrm{D}$ printed parts because the high crystallinity of PBS produced significant warpage, which prevented its use for practical purposes. On the contrary, the less crystalline PBSA random copolymer showed excellent performance during FFF. Thus, dimensionally stable and ductile printed objects were obtained, opening new processing routes for semi-crystalline biodegradable polyesters.
\end{abstract}

Key-words: Polybutylene succinate; poly (butylene succinate-ran-adipate); Fused Filament Fabrication; additive manufacturing; entanglements density 


\section{Introduction}

Customization and shorter time from design to manufacturing are some of the benefits of the Additive Manufacturing (AM) compared with injection molding. Consequently, its use is now widespread to manufacture parts in automotive, aeronautic, medical, construction, clothing, and other industries. There are different types of AM (3d printing) technologies, but Fused Filament Fabrication (FFF) has been recognized as the most useful and low-cost process for fabricating prototypes and functional parts with engineering plastics. A thermoplastic polymer filament is melted, and extruded from a hot nozzle. Later, the material is placed over a flatbed (support platform) layer by layer. Finally, when all the layers are completed the part is ready for use (1-2).

The final quality and the bonding and mechanical properties of FFF processed parts depends on the selection of processing conditions, which in turn depend on the rheology of the polymer: (a) Nozzle temperature is set to melt the filament; (b) Bed temperature is the temperature of the platform; (c) Printing velocity is the speed at which the nozzle moves over the bed while depositing the molten filament.

The FFF method has been extensively used with Poly (lactic acid) (3-6), Acrylonitrile-butadiene-styrene (7-10), and Thermoplastic Polyurethane (11-12). However, FFF techniques have been recently optimized to print other polymers as well, such as Polyether Ether Ketone (13-15), Polycarbonate (16-17), Polypropylene (18-19) and Thermoplastic Polyimide (20).

Recently, the development and application of biodegradable and biobased polymers have gained significant attention due to several environmental reasons. However, many characteristics of the biodegradable polymers, including thermal and mechanical properties, are still not as good as conventional polymer materials.

Some of the most important biodegradable polymers are poly(butylene succinate) (PBS) and its random copolymers with poly(butylene adipate), or poly (butylene succinateran-adipate) (PBSA) (21-22). One of these copolymers is now commercially available and has a composition of $80 \%$ PBS and $20 \%$ PBA (see experimental). Both of these semicrystalline polymers have some attractive features related to their good mechanical properties and service temperatures, as well as excellent processability by using conventional 
equipment, which makes them even comparable with some polyolefins. One of the shortcomings of these polymers is their relatively high price.

PBS is a biodegradable semi-crystalline aliphatic thermoplastic polyester. It has good melt-processability, thermal stability, and chemical resistance. The elongation at break and tensile strength are similar to common polyolefins (Polypropylene and LowDensity Polyethylene). PBS can be suitably processed by extrusion molding and injection molding. Because of its high crystallinity, it exhibits a lower biodegradability than its copolymers, which are less crystalline.

PBSA is a biodegradable thermoplastic copolyester composed of butylene succinate and butylene adipate repeating units randomly distributed along the chain (21-22). It has good melt-processability and chemical resistance (23-31). Some researchers have studied these materials for applications like packaging and have studied specially synthesized copolymers or commercially available samples (21-22, 29, 32-33).

PBS is considered to be a good candidate for 3D printing, because of its excellent ductility, processability, and relatively low melting point. However, we only found one publication dealing with 3D printing employing PBS (34) and none employing PBSA copolymer.

The suitability as filaments and the interlayer bond strength in 3D printing (FFF) was evaluated by Ou-Yang et al. (34). PBS/PLA blends with different compositions were studied. The tensile tests with dumbbell-shaped specimens were used to calculate the interlayer bond strength. The authors obtained an increase in the elongation at break and impact strength of the blends when the PBS content was increased. In addition, the interlayer bond strength improved due to the decreased melt viscosity. However, when the degree of crystallinity of the blends was increased, the distortion of the 3D printing specimens increased.

It is important to highlight that, at this moment, there are no standard test methods for the study of the mechanical strength and the adhesion resistance of parts manufactured using 3D printing. Each researcher adapts existing techniques for the evaluation of the mechanical properties of plastic parts (35-36) (tensile tests ASTM D638, ISO 527-2 and D3039, flexural tests ASTM D790 and ISO178, impact tests ISO 179, ASTM D6110, ISO 180 and ASTM D256, compression tests ASTM D695 and ISO604, shear tests ASTM D4255 and ISO 15310 , fatigue behavior ASTM D7774, creep ASTM D2990-09, fracture toughness ISO 15024, 
ASTM D5528, ISO 13586 and ASTM D6068), manufactured by conventional techniques (injection molding, extrusion molding and so on) and adequate to study the mechanical properties of 3D printed products.

It should be noted that the mechanical properties of AM parts can be affected by both the unprinted material properties and the manufacturing method. Interestingly enough, a technique that studies, in particular, the strength of the weld formed between two layers produced by AM (FFF) has been reported by Davis et al. (37) and Seppala et al. (38). These authors proposed to measure the mechanical strength of a FFF weld directly through a Mode III torsional test called Trouser tear. This procedure has been tested with Acrylonitrilebutadiene-styrene (ABS) thermoplastic amorphous material.

The objective of this paper is to study the thermal and rheological properties of biodegradable and semi-crystalline PBS and PBSA materials to correlate them with FFF processing feasibility, and in particular, with the interlayer adhesion and ductility. The role played by crystallinity degree, melt viscosity, and entanglements density on suitable printing conditions are discussed. The mechanical properties of 3D printed parts have been compared with injection-molded specimens.

\section{Materials and Methods}

\subsection{Materials}

Two commercial thermoplastic extrusion grade biodegradable polymers, polybutylene succinate (PBS) and poly (butylene succinate-ran-adipate) (PBSA), in pellets, were employed. Specifically, the PBS denoted PBE003 Natureplast (France) with an MFI (190/2.16) of $4-6 \mathrm{~g} / 10$ min and the PBSA named PBE001 Natureplast (France) with an MFI $(190 / 2.16)$ of $4-5 \mathrm{~g} / 10 \mathrm{~min}$ were used. The PBSA has a $21 \pm 1 \mathrm{~mol} \%$ of butylene-adipate groups according to ${ }^{1} \mathrm{H}$ NMR results (39).

The average molecular weights of the specimens were measured by Size Exclusion Chromatography (SEC) at the Universitat Politècnica de Catalunya (UPC), using an Agilent chromatography apparatus equipped with a pump, an autosampler and an Agilent ultraviolet detector working at $220 \mathrm{~nm}$ (Santa Clara, CA, USA). The analyses were performed at $25^{\circ} \mathrm{C}$ and $0.8 \mathrm{~mL} \cdot \mathrm{min}^{-1}$ in hexafluoroisopropanol (HFIP), containing sodium trifluoroacetate (concentration 0.05 mole/L), from Apollo Sci (Bredbury, UK) on a PLgel column from 
Polymer Laboratories Ltd (Palo Alto CA, USA) with $10 \mu \mathrm{m}$ particle size. For PBS the obtained average molecular weights were $M_{n}=19800 \mathrm{~g} / \mathrm{mol}, M_{w}=79250 \mathrm{~g} / \mathrm{mol}$ and $M_{z}=$ $163200 \mathrm{~g} / \mathrm{mol}$ and for PBSA, $M_{n}=12300 \mathrm{~g} / \mathrm{mol}, M_{w}=78600 \mathrm{~g} / \mathrm{mol}$ and $M_{z}=172500 \mathrm{~g} / \mathrm{mol}$.

\subsection{Elaboration of filaments}

The polymers were dried for $24 \mathrm{~h}$ in a dehumidifier at $80^{\circ} \mathrm{C}$ to remove moisture before processing. The PBS and PBSA filaments to be employed in Fused Filament Fabrication (FFF) 3D Printing were made with a Collin Teach-line ZK-25 twin-screw co-rotating extruder (25 $\mathrm{mm}$ diameters with $\mathrm{L} / \mathrm{D}$ relationship of 18:1). The screw rotational speed and the nozzle temperature were fixed at $50 \mathrm{rpm}$ and $150^{\circ} \mathrm{C}$, respectively. To cool down the produced filaments, a bath with closed circulation of water at room temperature was employed. PBS and PBSA filaments with a nominal diameter of $1.75 \mathrm{~mm}$ were obtained.

\subsection{Thermal characterization of the material}

\subsubsection{Differential scanning calorimetry (DSC)}

A Perkin Elmer DSC 8000 equipped with an Intracooler 2 was used to determine melting and crystallization parameters. All the DSC experiments were carried out under ultra-pure nitrogen flow. Encapsulated samples in aluminum with an approximate weight of $7 \mathrm{mg}$ were employed. The DSC was calibrated with indium and tin standards. All samples were heated and cooled between $20^{\circ} \mathrm{C}$ to $180^{\circ} \mathrm{C}$ at a cooling and heating rate of $20^{\circ} \mathrm{C} / \mathrm{min}$. From the fusion enthalpy, the degrees of crystallization were calculated with the following equation:

$$
X_{c}=\frac{\Delta H_{m}}{\Delta H_{m}{ }^{0}} * 100
$$

where $\Delta H_{m}(\mathrm{~J} / \mathrm{g})$ is the melting enthalpy of the sample and $\Delta H_{m}{ }^{0}$ is the melting enthalpy of a $100 \%$ crystalline polymer. The value $\Delta H_{m}{ }^{0}=213 \pm 10 \mathrm{~J} / \mathrm{g}$ recently determined by Arandia et al. (40) for PBS was used. In the case of PBSA, $X_{c}$ was normalized by composition, dividing it by the PBS weight fraction in the copolymer (40).

\subsubsection{Dynamic Mechanical Thermal Analysis (DMTA)}


A Dynamic Mechanical Thermal Analyzer, Triton 2000 DMA from Triton Technology, was used in bending deformation mode. The samples were heated from $-130{ }^{\circ} \mathrm{C}$ to $130{ }^{\circ} \mathrm{C}$ at a constant rate of $4{ }^{\circ} \mathrm{C} / \mathrm{min}$ and a constant frequency of $1 \mathrm{~Hz}$. The tests were performed at low strain amplitudes, ensuring a linear viscoelastic response. Measurements were carried out to determine the glass transition temperature, $T_{g}$, taken as the maximum peak in loss tangent, $\tan \delta$.

\subsubsection{Pressure-Volume-Temperature (PVT) measurements}

PVT measurements of PBS and PBSA were carried out in a PVT100 apparatus of the piston die type made by Haake (Germany). An isobaric cooling mode procedure in the pressure range from 200 to 1600 bar with a cooling rate of $30^{\circ} \mathrm{C} / \mathrm{min}$ was employed. The results at a pressure of 1 bar were obtained by extrapolation to the Tait model.

\subsubsection{Rheological measurements}

The rheological properties were determined using a strain-controlled ARES-G2 rotational rheometer from TA Instruments. The experiments were run under nitrogen flow using a $25 \mathrm{~mm}$ diameter parallel-plate configuration with PBS and PBSA disks of approximately $1 \mathrm{~mm}$ thickness. Viscoelastic functions such as elastic modulus, $G$, viscous modulus, $G^{\prime \prime}$, and complex viscosity $\eta^{*}$, were measured in the linear viscoelastic regime (strain amplitude below $0.5 \%$ ) in a frequency range of 0.03 to $100 \mathrm{rad} / \mathrm{s}$ at varying temperatures from $150^{\circ} \mathrm{C}$ to $230^{\circ} \mathrm{C}$.

The time-temperature superposition (TTS) principle was used to shift frequency data into a single master curve at a reference temperature of $190^{\circ} \mathrm{C}$, using a horizontal shift factor that depends on temperature following a Williams-Landel Ferry (WLF) or Arrhenius like equation (41).

Continuous flow measurements were also carried out in the same rheometer to test the validity of the Cox-Merz rule (42):

$$
\left|\eta^{*}(\omega)\right|=\sqrt{\eta^{\prime}(\omega)^{2}+\eta^{\prime \prime}(\omega)^{2}}=\left.\eta(\dot{\gamma})\right|_{\dot{\gamma}=\omega} \quad \text { (Eq. 2) }
$$


where $\eta^{*}$ is the complex viscosity, $\eta^{\prime}$ the real part of the complex viscosity, $\eta^{\prime \prime}$ the imaginary part of the complex viscosity and $\eta(\dot{\gamma})$ the viscosity function obtained in continuous flow at the corresponding shear rates $\dot{\gamma}$.

\section{$2.43 \mathrm{D}$ printing}

PBS and PBSA parts were manufactured using a TUMAKER Voladora V1 FFF machine from Tumaker (Spain), controlled with Simplify3D software by Creative Tools AB. This software was used to generate G-code and to control all the process conditions. The maximum printing size was $22 \times 22 \times 30 \mathrm{~cm}$ (length, width, and height respectively) with a nozzle diameter of $0.4 \mathrm{~mm}$. Filaments with a nominal diameter of $1.75 \mathrm{~mm}$ were employed.

\subsection{Printing parameters}

To find the most adequate printing conditions, seven different combinations of variables (Table 1) were established by varying the printing velocity and the bed temperature (five specimens for set of condition). Table 1 outlines the $3 \mathrm{~d}$ printing process conditions used in this study. The layer height, fill density and fill pattern setting were kept constant at 0.3 $\mathrm{mm}, 100 \%$ and rectilinear $0^{\circ}$ respectively. Parts were placed on-edge build orientation.

Table 1. Process conditions studied in this work.

\begin{tabular}{cccc}
\hline Condition & $\begin{array}{c}\text { Nozzle } \\
\text { temperature } \\
\left({ }^{\circ} \mathrm{C}\right)\end{array}$ & $\begin{array}{c}\text { Bed temperature } \\
\left({ }^{\circ} \mathrm{C}\right)\end{array}$ & $\begin{array}{c}\text { Printing } \\
\text { velocity } \\
(\mathrm{mm} / \mathrm{s})\end{array}$ \\
\hline L11 & 190 & 25 & 2.0 \\
L12 & 190 & 25 & 3.5 \\
L13 & 190 & 25 & 5.0 \\
L14 & 190 & 25 & 6.5 \\
L15 & 190 & 25 & 9.5 \\
L23 & 190 & 30 & 5.0 \\
L33 & 190 & 35 & 5.0 \\
\hline
\end{tabular}


These samples will be used for the determination of the trouser force of the interphase following the recommendations given in section 2.6.

\subsection{Trouser Geometry}

There are no standard test methods for determining adhesion between layers of manufactured parts using FFF. Here, we define the interfacial bonding strength achieved between two layers as the trouser strength. The ASTM 1938-14 method (43) was adapted to determine trouser strength, using a commercial mechanical testing machine. The geometry of the $3 \mathrm{D}$ printed specimens was drawn using Tinkercad software. Then they was exported as an STL file and finally, imported to the $3 \mathrm{D}$ printing software. The main dimensions of the specimen are shown in Figure 1a. A pre-crack of $60 \mathrm{~mm}$ was built in the trouser specimens. The printing was paused $5 \mathrm{~s}$, between layers 41 and 42, to insert across the center of the sample, a $0.01 \mathrm{~mm}$ wide piece of aluminum paper (Figure 2).

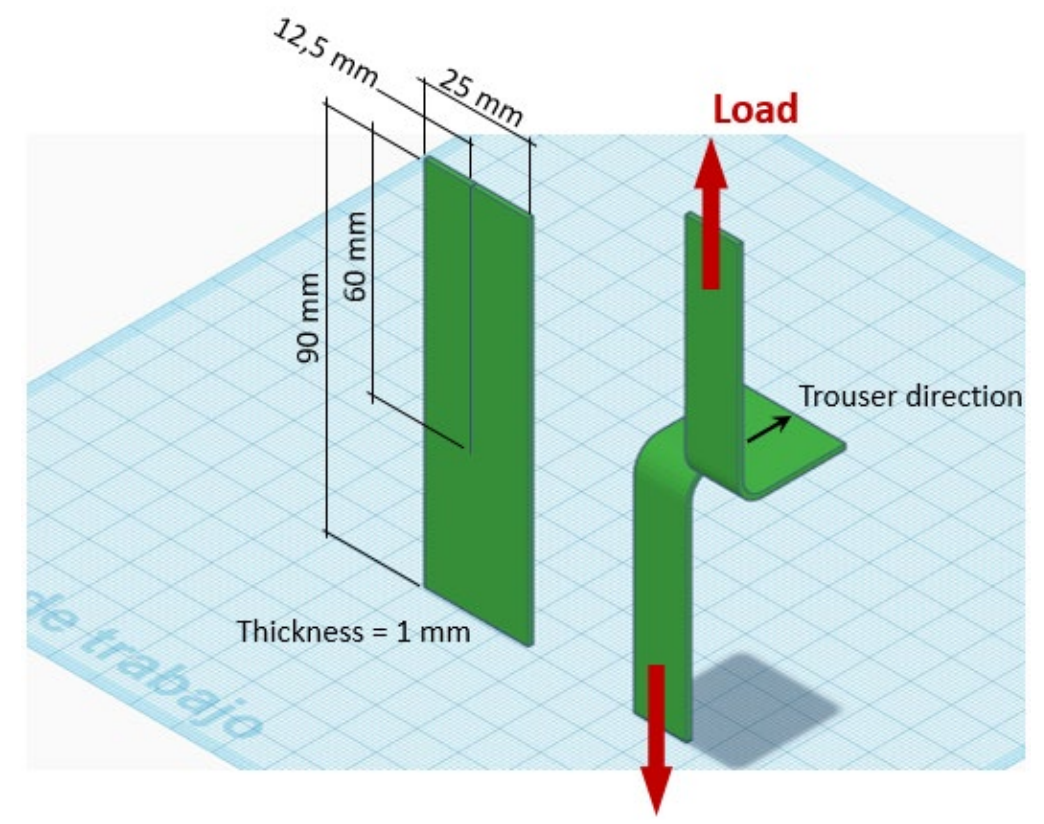

(a)

(b)

Figure 1: (a) Dimensions of trouser specimen and (b) trouser direction.

\subsection{Welding strength}

The tearing force of the weld between two 3D printing layers was determined by a Mode III fracture test, also called Trouser tear test. The tear test applies a force to a polymer 
that already contains a pre-crack (tear) to bring the material to complete failure. ASTM D1938-14 test method (43) for films was slightly modified to measure the tearing energy of the $3 \mathrm{D}$ printing samples.

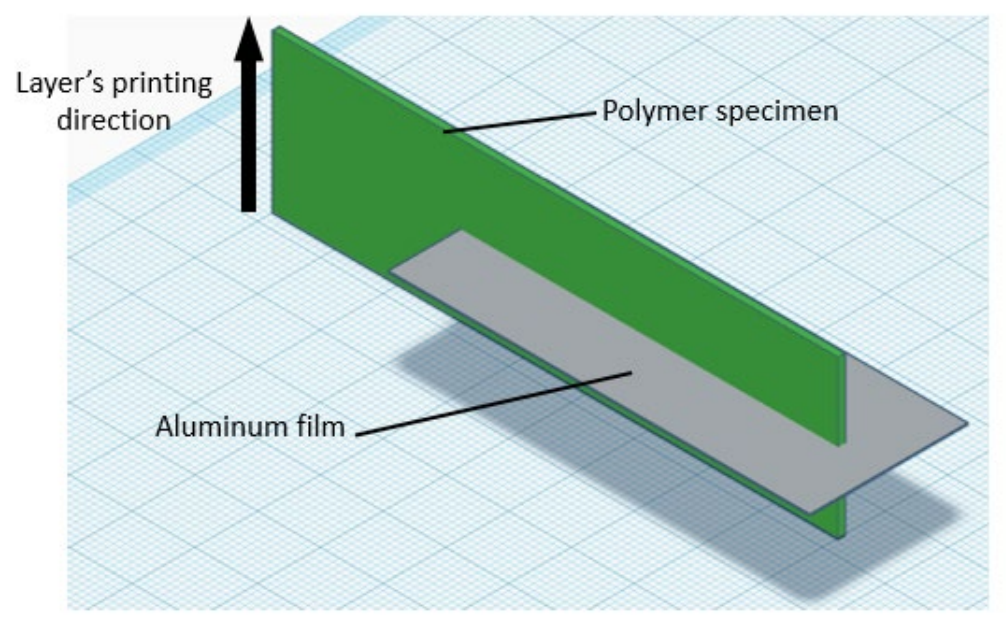

Figure 2. Placement of aluminum paper in the trouser test specimen.

This was done by placing the test sample into a tensile testing or universal INSTRON 5569 testing machine with $50 \mathrm{~mm}$ of distance between the jaws and a test speed of 254 $\mathrm{mm} / \mathrm{min}$ (Figure $1 \mathrm{~b}$ ).

The test proceeds until tearing has propagated through the entirety of the sample and the two sections have been completely separated from one another. The curves which correspond to tearing forces versus displacement (or time) obtained for PBS and PBSA were similar to those obtained from Low-Extensible thin films and sheeting (43). As it is indicated in Figure 3, the tearing force is calculated by averaging the load over a $25.4 \mathrm{~mm}$ (1 inch) interval, disregarding the initial (first peak) and final portions of the curve. 


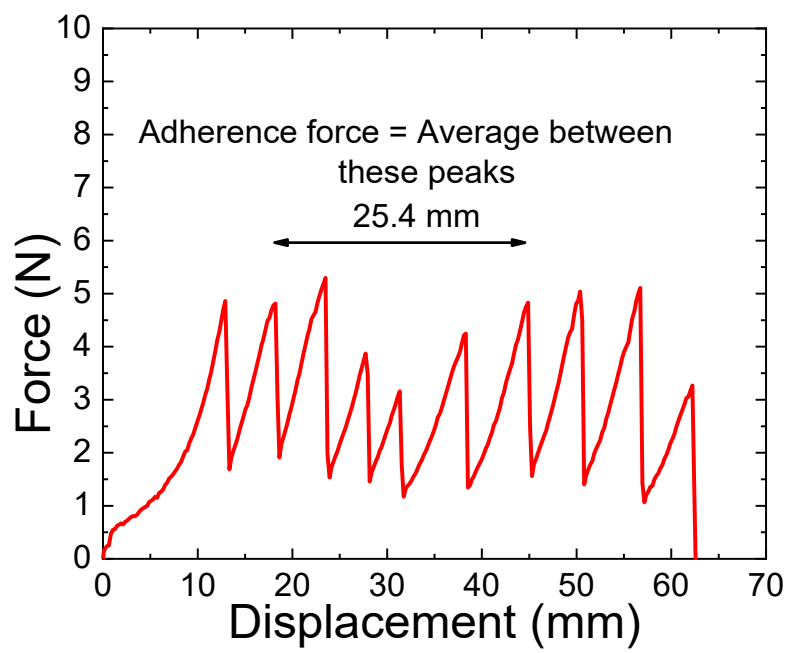

Figure 3. Typical result of the tearing force of a trouser specimen (shown in Figure 2).

\subsection{Cross-sectional morphology}

The welding line between two filaments was observed by Polarized Light Optical Microscopy (PLOM) (Olympus BX51) and analyzed by Scanning Electron Microscope (SEM). The SEM analysis was performed using a Hitachi S-2700 microscope with accelerating voltages of $15 \mathrm{kV}$. The sample surfaces were gold ( $\mathrm{Au}$ ) coated by means of a Bio-Rad Microscience Division SC500 sputter Coater.

The cross-sections of different specimens were prepared by cryogenic fracture in liquid nitrogen to obtain the actual width of the weld line resulting from different process conditions. A digital camera was used to capture images of the printing filaments and the welding lines. Image analysis software (Image J) was used to measure the diameter and sizes of the printing filaments and the relevant weld line length, as it is represented in Figure 4.

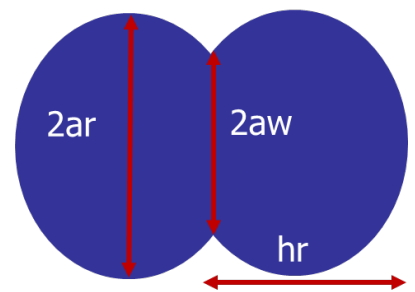

Figure 4. Representation of the dimensions of the weld line between two 3D printed filaments $\left(2 \mathrm{a}_{\mathrm{w}}=\right.$ welding line length, $2 \mathrm{a}_{\mathrm{r}}=$ larger diameter of the filament and $\mathrm{h}_{\mathrm{r}}=$ smaller diameter of the filament). 


\subsection{Weld tearing energy}

Following the criterion of Davis et al. (37) and Seppala et al. (38), the average tearing force $\left(F_{t}\right)$ of the weld of two 3D printing layers obtained from the universal testing machine was normalized with the welding line length $\left(2 a_{w}\right)$ between the filaments (obtained from SEM photographs) to calculate the weld tearing energy $\left(\sigma_{t}\right)$ :

$$
\sigma_{t=\frac{F_{t}}{2 a_{w}}}
$$

The good welding of the filaments during the FFF process was checked by PLOM.

\subsection{Mechanical properties}

A universal testing machine INSTRON 5569 was used to perform tensile stress-strain tests to Type IV Tensile Test Specimens (ASTM D638) (44) obtained by FFF at a cross-head speed of $20 \mathrm{~mm} / \mathrm{min}$.

For comparative purposes, PBSA specimens with the same dimensions were obtained by injection molding and tested. The injection molding machine employed was a Battenfeld BA-230-E equipped with a reciprocating screw with a diameter of $18 \mathrm{~mm}$, an L/D ratio of 17.8 and a maximum closing force of 23 tones. The melt and mold temperatures were $150^{\circ} \mathrm{C}$ and $15^{\circ} \mathrm{C}$, respectively.

\section{Results and discussion}

\subsection{Thermal properties}

Figure 5 shows DSC heating and cooling scans for both samples employed here. In the first heating scan of the as received samples, the materials have an unknown thermal history imposed by the processing applied by the corresponding manufacturers. The main melting peak temperature for neat PBS is much higher than that for the PBS-rich phase in PBSA, as expected (see ref. 21 for analogous results on similar materials). The commercial PBSA employed here only contains $20 \%$ poly(butylene adipate). Hence, only the PBS-rich phase within the copolymer can crystallize (21).

After the thermal history is erased by heating the samples to $140^{\circ} \mathrm{C}$, the samples were cooled from the melt and both samples show bimodal crystallization exotherms, whose origin 
is unknown but could be related to the polymorphism that PBS can exhibit during crystallization. In the second heating curves (Figure 5c), the materials exhibit cold crystallization, followed by a single melting. Reorganization during the scan is of common occurrence in polyesters and the presence of two polymorphs, if they exist, would have to be corroborated by temperature-dependent WAXS. However, these experiments are outside the scope of the present contribution. A summary of the calorimetric values obtained from the DSC scans is presented in Table 2. The values are similar to those reported in the literature for similar materials (21).

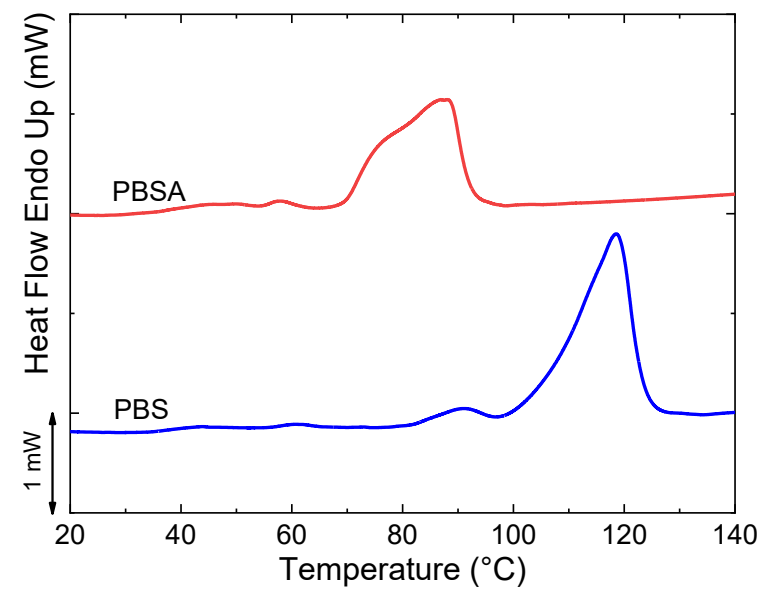

(a)

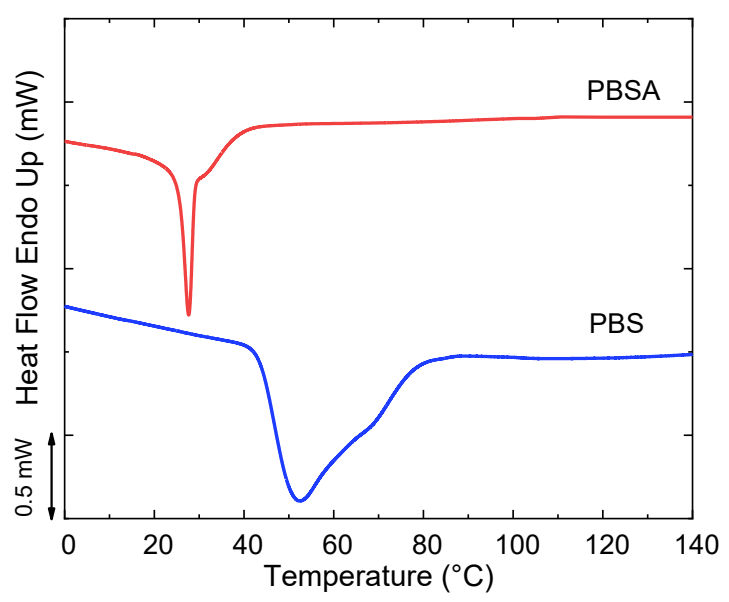

(b)

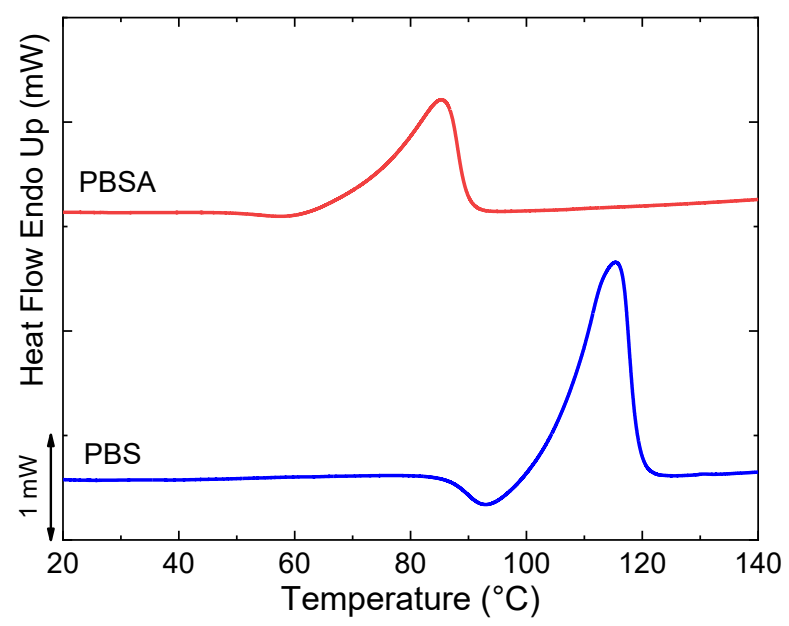

(c)

Figure 5. (a) DSC scans obtained during the first heating of as-received samples. (b) DSC cooling scans from the melt. (c) Subsequent heating scans $\left(2^{\text {nd }}\right.$ heating). 
Table 2. Melting and crystallization temperatures (taken at the respective peaks), enthalpies and crystallinity degrees determined from DSC curves (PBSA and PBS).

\begin{tabular}{ccccccccccccc}
\hline Material & \multicolumn{3}{c}{ First heating } & \multicolumn{3}{c}{ Cooling } & \multicolumn{5}{c}{ Second heating } \\
& $T_{m 1}$ & $\Delta H_{m}$ & $\% X_{c}$ & $T_{c}$ & $\Delta H_{c}$ & $\% X_{c}$ & $T_{c c}$ & $\Delta H_{c c}$ & $\% X_{c}$ & $T_{m 2}$ & $\Delta H_{m}$ & $\% X_{c}$ \\
& $\left({ }^{\circ} \mathrm{C}\right)$ & $(\mathrm{J} / \mathrm{g})$ & & $\left({ }^{\circ} \mathrm{C}\right)$ & $(\mathrm{J} / \mathrm{g})$ & & $\left({ }^{\circ} \mathrm{C}\right)$ & $(\mathrm{J} / \mathrm{g})$ & & $\left({ }^{\circ} \mathrm{C}\right)$ & $(\mathrm{J} / \mathrm{g})$ & \\
\hline PBSA & 85 & 46.3 & 27 & 27 & 43.2 & 25 & 57 & 0.3 & 0.2 & 86 & 41.3 & 24 \\
PBS & 118 & 62.1 & 29 & 52 & 63.5 & 30 & 93 & 7.6 & 4 & 116 & 58.3 & 27 \\
\hline
\end{tabular}

The crystallization process was also studied using Pressure-Volume-Temperature (PVT) experiments. PVT tests analyze the volume decrease during crystallization, which is related to the warpage often observed in $3 \mathrm{D}$ printing of semi-crystalline polymers. The results obtained at a cooling rate of $30^{\circ} \mathrm{C} / \mathrm{min}$ are presented in Figure 6. Respective arrows indicating the onset of crystallization of each polymer, detected by DSC at a cooling rate of $20^{\circ} \mathrm{C} / \mathrm{min}$, remark the matching of the data of both PVT and DSC, techniques.

As expected, increasing the cooling rate leads to a shift of the crystallization process to lower temperatures. Indeed, the cooling rates in real 3D printing processes are much higher than our value of $30^{\circ} \mathrm{C} / \mathrm{min}$ (38), which implies a shift of the crystallization process to lower temperatures than those reported in Figure 6. A typical bed temperature for 3D printing employed in this work (Table 1 ) is $25^{\circ} \mathrm{C}$, which is indicated with a line in the figure to remark the differences found between both polymers in the printing process. It is deduced that from $100^{\circ} \mathrm{C}$ to $25^{\circ} \mathrm{C}$ the specific volume changes $\Delta \mathrm{V}=0.075 \mathrm{~cm}^{3} / \mathrm{g}(8.6 \%)$ for PBS, but $\Delta \mathrm{V}=0.039$ $\mathrm{cm}^{3} / \mathrm{g}(4.3 \%) \mathrm{cm}^{3} / \mathrm{g}$ for PBSA copolymer, because of its lower crystallization temperature.

This thermal difference has dramatic consequences for $3 \mathrm{D}$ printing, since a considerable warpage is observed only for the objects elaborated with PBS, as reported in Section 4. This represents an interesting example of how a change in the microstructure of the polymer chains can determine the feasibility of additive manufacturing. 


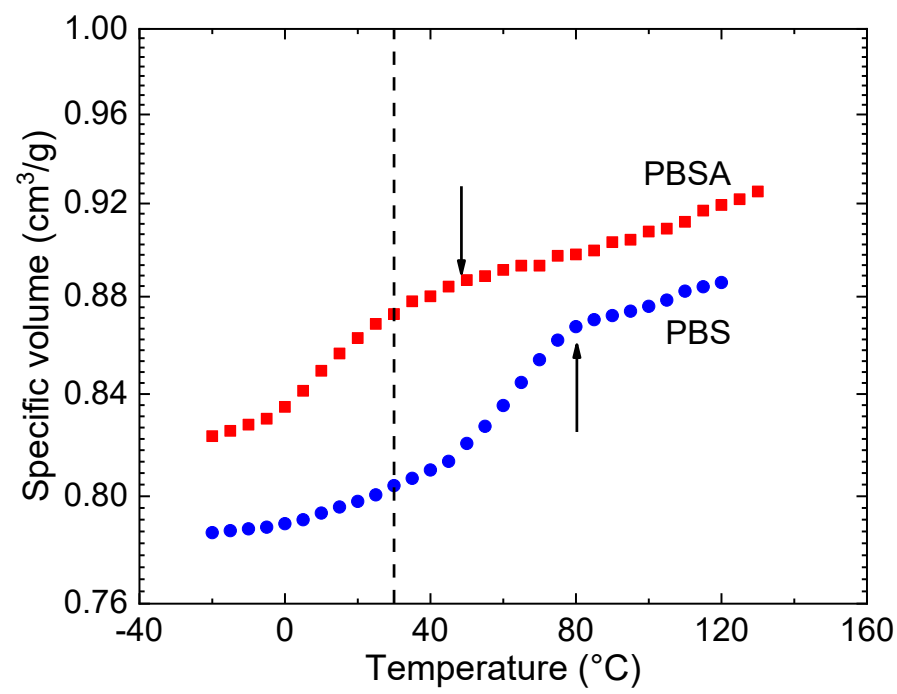

Figure 6: Volume-temperature results at a pressure of 1 bar and cooling rates of $30^{\circ} \mathrm{C} / \mathrm{min}$. The arrows indicate the corresponding temperatures for the onset of crystallization of PBS and PBSA as obtained by DSC, and the vertical line marks the temperature of the bed in the $3 \mathrm{D}$ printing process $\left(\mathrm{T}=25^{\circ} \mathrm{C}\right)$.

Dynamic Mechanical Thermal Analysis (DMTA) carried out with both samples allows determining the transition from the glassy to the rubbery state. As can be seen in Figure 7, only a single glass transition temperature, taken at the maximum of the loss tangent curve, is observed for PBSA, confirming the random nature of this copolymer, as already reported in the literature (21). The glass transition temperature of PBS is $T_{g}=-22^{\circ} \mathrm{C}$, whereas the $T_{g}$ of the PBSA copolymer is $-34^{\circ} \mathrm{C}$, revealing the plasticizing effect of poly (butylene adipate), PBA, which has a much lower glass transition temperature, $T_{g}=-59.2^{\circ} \mathrm{C}(21)$. 


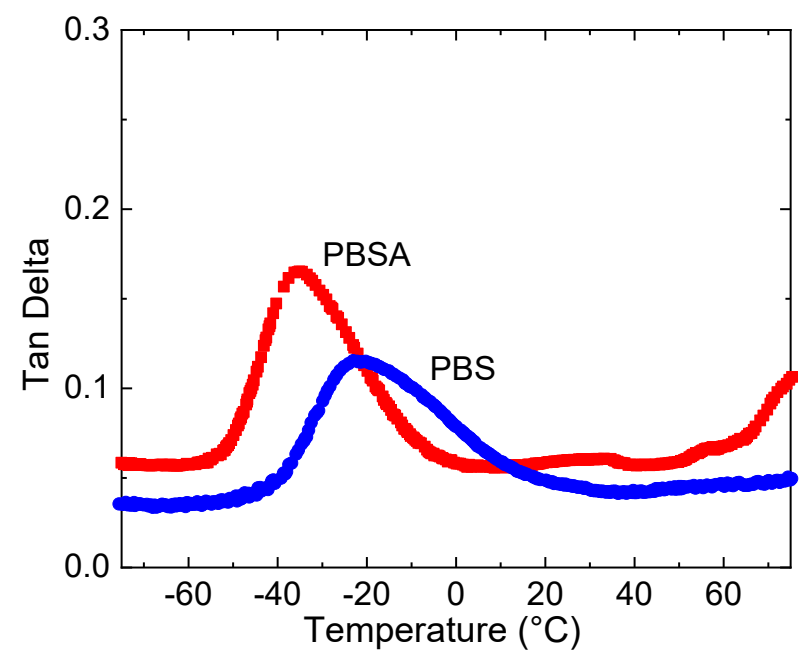

Figure 7. Variation of the loss tangent with temperature at a constant frequency of $1 \mathrm{~Hz}$ and a heating rate of $4^{\circ} \mathrm{C} / \mathrm{min}$.

3.2 Dynamic viscoelastic results in the molten state

Oscillatory flow experiments at small amplitudes, or Small Amplitude Oscillatory Shear (SAOS) measurements, in the molten state, allow testing materials behavior in two crucial aspects of 3D printing: a) Flowability of the molten polymers into the nozzle and b) Welding of layers, which is linked to entanglements diffusion.

To get an easy flowing material, and avoid buckling of the solid part of the filament when pushing the molten part into the nozzle, the viscosity should not exceed certain values. So far, there is not a rule of thumb, but according to our experience, the viscosity should not be higher than $10^{5} \mathrm{~Pa}$.s in the shear rate interval involved in printing. The viscosity results of our samples at a temperature of $190^{\circ} \mathrm{C}$ are displayed in Figure 8. As can be seen, in this figure, the aforementioned Cox-Merz rule (see Experimental Part) was tested, having in mind that this rule does not hold for phase-separated or complex polymer systems. 


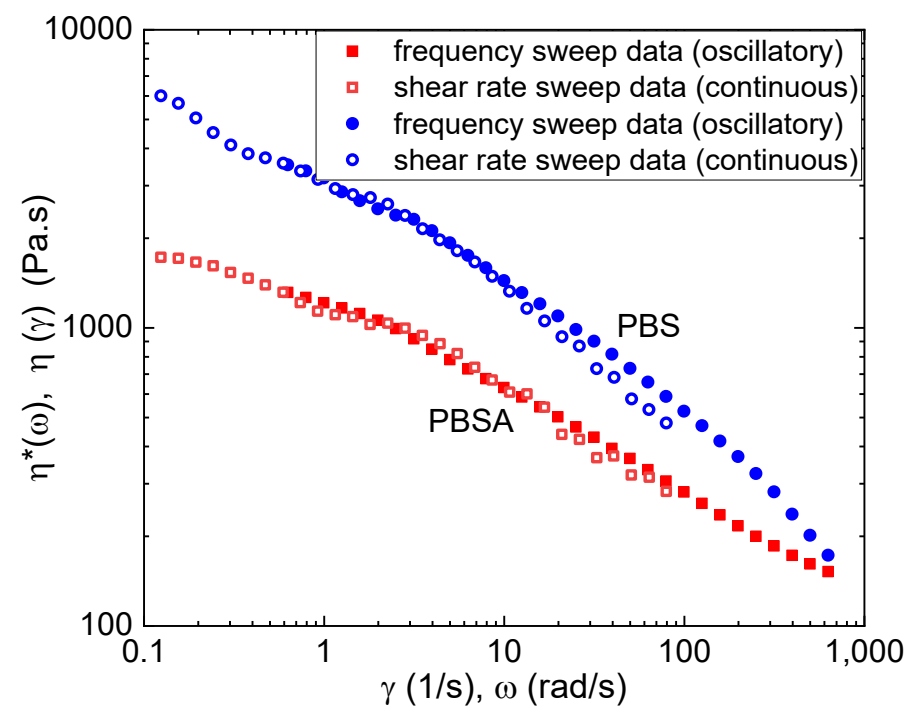

Figure 8. Overlapped plots of the continuous flow viscosity versus shear rate $(\eta(\gamma))$ and complex viscosity versus frequency $\left(\eta^{*}(\omega)\right)$ of PBS and PBSA to test Equation

2.

In our case, the Cox-Merz equation holds particularly well for PBSA random copolymer, which suggests that the ratio of monomers should be very similar in all the chains, as expected for polyester random copolymers prepared by controlled polycondensation reactions. The random nature of a similar PBSA copolymer was demonstrated by NMR analysis and reported recently (21). The viscosity values of both samples lie below $10^{4} \mathrm{~Pa} . \mathrm{s}$, which allows forecasting a suitable flow in the nozzle. To confirm this assertion, viscosity data of commercial acrylonitrile-butadiene-styrene (ABS) and polylactic acid (PLA) samples, widely used in filament-based 3D printing, are included in Figure 9 for comparison purposes. The viscosity values of both PBS and PBSA, at $190^{\circ} \mathrm{C}$ lie between those of the commercial samples at their corresponding ideal temperatures for 3D printing. Therefore, before other conclusive results, it can be said that our biodegradable polymers require less energy (lower temperatures) than other polymers commercially available for FFF. 


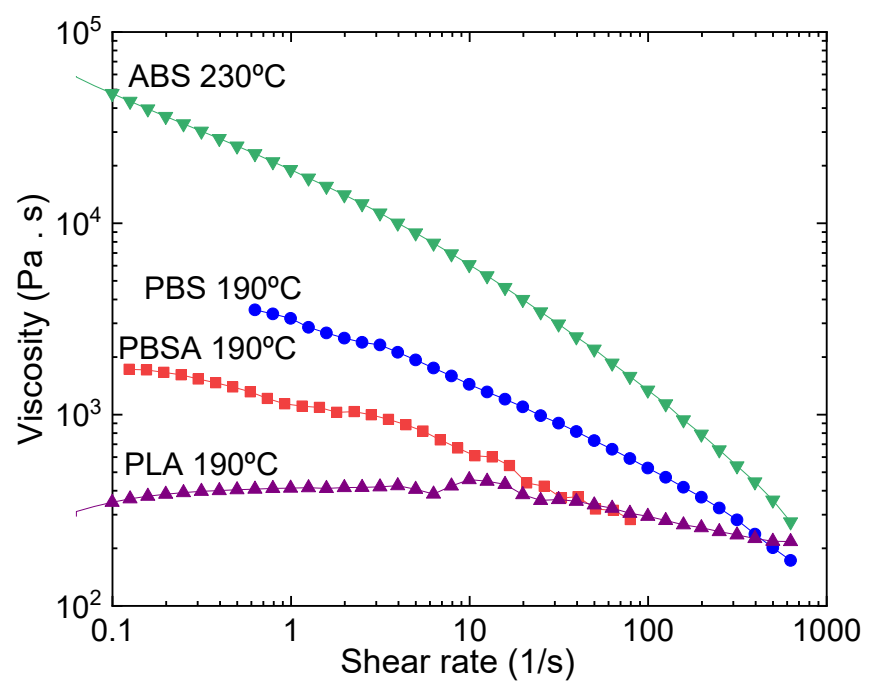

Figure 9. Comparison of the viscosity of printable commercial materials (ABS and PLA) with PBS and PBSA samples. The observed fluctuations of viscosity are due to experimental flow instabilities.

In recent years, research on the role played by polymer chain entanglements in the welding of 3D printing layers has gained interest $(37-38,45)$. To obtain the necessary relevant parameters, studies of the viscoelastic behavior of the involved polymers in the terminal zone, also called flow region, must be performed. Although very valuable results can be obtained using stress relaxation and creep experiments to analyze the viscoelastic terminal zone, currently small amplitude oscillatory shear (SAOS) measurements are preferred by most polymer researchers. The variation of both elastic G' and viscous G" moduli, with frequency at different constant temperatures in the molten state, allows making master curves using the time-temperature superposition. Besides the terminal zone, the onset of the rubbery zone can also be investigated, allowing, in many cases, to determine the entanglements modulus $G_{N}{ }^{0}$.

The $G$ ' and $G$ ' master curves obtained at a reference temperature of $T_{r}=190^{\circ} \mathrm{C}$ using an $a_{T}$ shift factor are displayed in Figure 10. The application of time-temperature superposition holds for both samples, PBS homopolymer, and PBSA copolymer. As for the fulfillment of the Cox-Merz rule, the nice superposition observed for PBSA constitutes another proof of the molecular homogeneity of this copolymer. It is known that small heterogeneities in the chain architecture, like a non-homogeneous distribution of long-chain branches, as well as 
microphase separation, bring about a failure of the time-temperature superposition. The shift factor is given by the William-Landel-Ferry (WLF) equation (Eq. 4) for the PBSA; but in the case of the PBS a better fit is obtained with the Arrhenius equation (Eq. 5), which is actually a simplified case of the WLF equation (41).

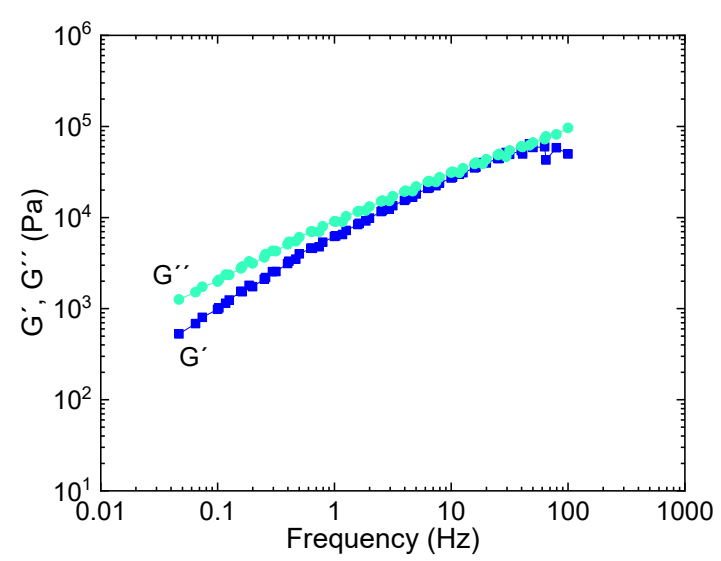

(a)

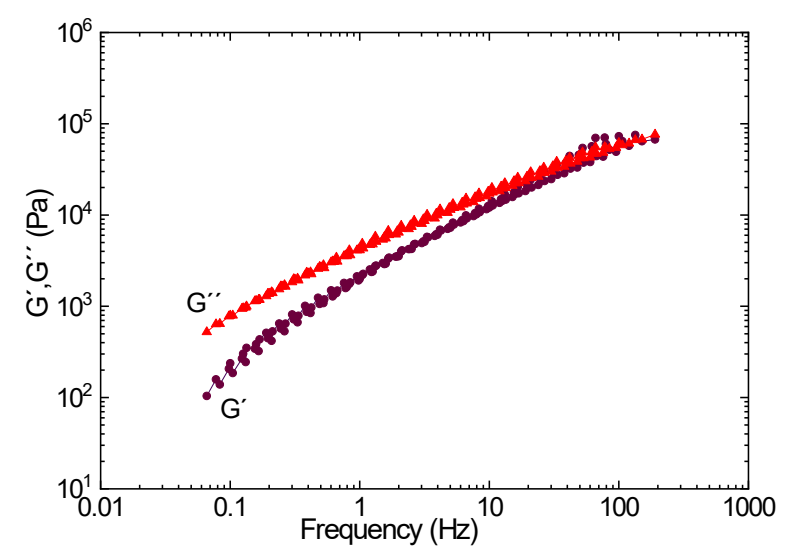

(b)

Figure 10. Master curves of the elastic and viscous moduli at a reference temperature of $190^{\circ} \mathrm{C}$ (a) PBS and (b) PBSA.

$$
\log \left(a_{T}\right)=\frac{-1.089(T-463.1)}{195.7+(T-463.1)} \quad \text { (Eq. 4) }
$$

where $T_{r}=190^{\circ} \mathrm{C}(463.1 \mathrm{~K})$ is the reference temperature chosen to construct the master curves and $C_{1}=1.089, C_{2}=195.7$ are empirical constants adjusted to fit the values of the superposition parameter or shift factor $a_{T}$.

In the case of PBS, the shift factor is given by:

$$
a_{T}=A e^{-\frac{E_{a}}{R T}}
$$

where $A$ is a pre-exponential factor, $R$ is the universal gas constant and $E_{\mathrm{a}}=20.83 \mathrm{KJ} / \mathrm{mol}$ is the activation energy of flow obtained from Eq. 5.

Among the methods proposed to obtain the entanglement modulus $G_{N}{ }^{0}(46)$, our results only allow the use of the following equation of Nobile-Cocchini (47): 


$$
\log G_{N}^{0}=\frac{-0.524+0.341 \log \left(\frac{M_{w}}{M_{n}}\right)-1.843 \log \left(\frac{M_{Z}}{M_{W}}\right)}{1-0.559 \log \left(\frac{M_{W}}{M_{n}}\right)+0.841 \log \left(\frac{M_{Z}}{M_{w}}\right)}-\log G_{x}
$$

where $G_{x}$ is the value of the elastic modulus at the crossing point $G^{\prime}=G^{\prime}$ ' and $M_{n}, M_{w}$ and $M_{z}$ are given in the Experimental part. $G_{x}$ values obtained from Figure 10 are $7 \times 10^{4} \mathrm{~Pa} . \mathrm{s}$ and $4 \times 10^{4}$ Pa.s for PBS and PBSA, respectively. These data give the following values for the entanglement modulus $G_{N}{ }^{0}: 0.51 \mathrm{MPa}$ for PBS and 0.56 MPa for PBSA. We assume that the generally accepted equation, Eq. 7, is valid in this case:

$$
G_{N}{ }^{0}=\rho R T / M_{e} \quad \text { (Eq. 7) }
$$

The entanglement number of the melt in the absence of shear is given by $Z_{e}=M_{w} / M_{e}$, which considering the molecular weights of the samples, is $Z_{e}=8$ and $M_{e}=9,900 \mathrm{~g} / \mathrm{mol}$ for PBS and $Z_{e}=9$ and $M_{e}=8,750 \mathrm{~g} / \mathrm{mol}$ for PBSA. An analysis of the $Z_{e}$ values found in literature for printable polymers reveals the following results: $Z_{e}=17$ for a polylactic acid (PLA) which has $M_{w}=156,000 \mathrm{~g} / \mathrm{mol}$ and $M_{e}=9,000 \mathrm{~g} / \mathrm{mol}(48) ; Z_{e}=9$ for an acrylonitrilebutadiene-styrene (ABS) with $M_{w}=90,000 \mathrm{~g} / \mathrm{mol}$ and $M_{e}=10,400 \mathrm{~g} / \mathrm{mol}$ (deduced from Seppala et al. 38) and $Z_{e}=37$ for polycarbonate (45).

In the next section, these data are used to discuss the welding strength values between layers, within the framework of the model developed by McIlroy and Olmsted (45).

\subsection{Strength of welding: Trouser test}

The fracture strength of an individual weld line of PBS and PBSA 3D printing specimens was studied by using "trouser tear" or Mode III testing described in the Experimental part. The average tearing force was obtained from the force vs. crosshead displacement at the different printing conditions. Examples of representative force vs. displacement curves for both polymers at the same printing conditions (L13) are shown in Figure 11. 


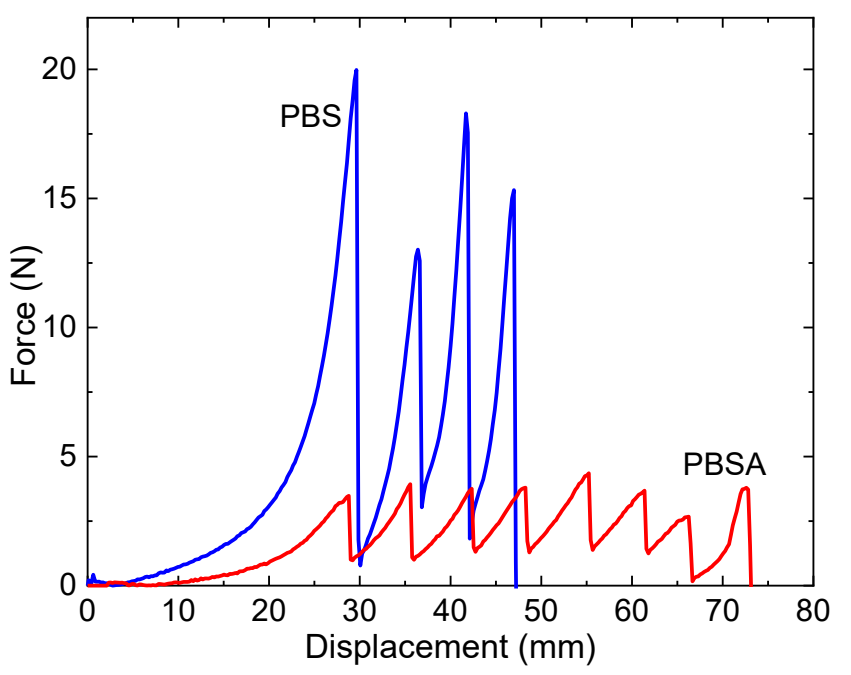

Figure 11. Force vs. crosshead displacement for PBSA and PBS printed with L13 process conditions (see Table 1).

The force needed to propagate the pre-made crack shows different patterns in both samples. The behavior of the PBS corresponds to a brittle material that has little plastic deformation and low energy absorption before fracture. But PBSA has a ductile behavior with an extensive plastic deformation and energy absorption ("toughness") before fracture.

Following the analysis of Seppala et al. (38), the tearing energy is given by the average force value during steady state-crack propagation (see Figures 3 and 11) divided by the weld line length of the filament after 3D printing, $a_{w}$, described in Figure 4:

$$
\sigma_{t=\frac{F_{t}}{2 a_{w}}}
$$

The good quality welding of the filaments is shown in Figure 12. PLOM shows a cross-section of two welded filaments on a microtomed slice of the 3D printed PBSA sample obtained under L13 process conditions. 


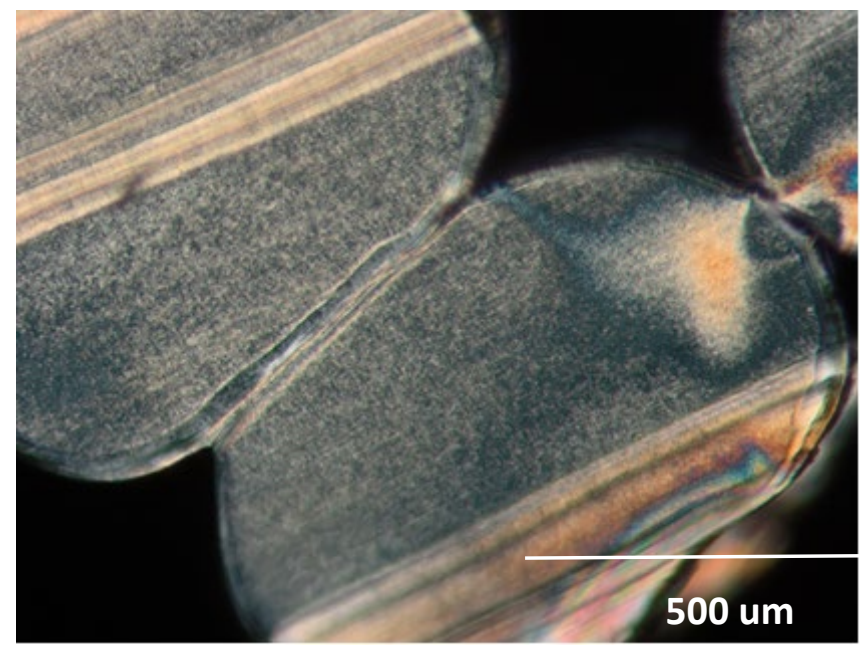

Figure 12. PLOM micrograph of the welding line between 3D printed layers of PBSA, printed employing L13 process conditions (see Table 1).

SEM micrographs, like that of Figure 13, are needed to determine the corresponding welding line length, $a_{w}$, of the welded filaments.

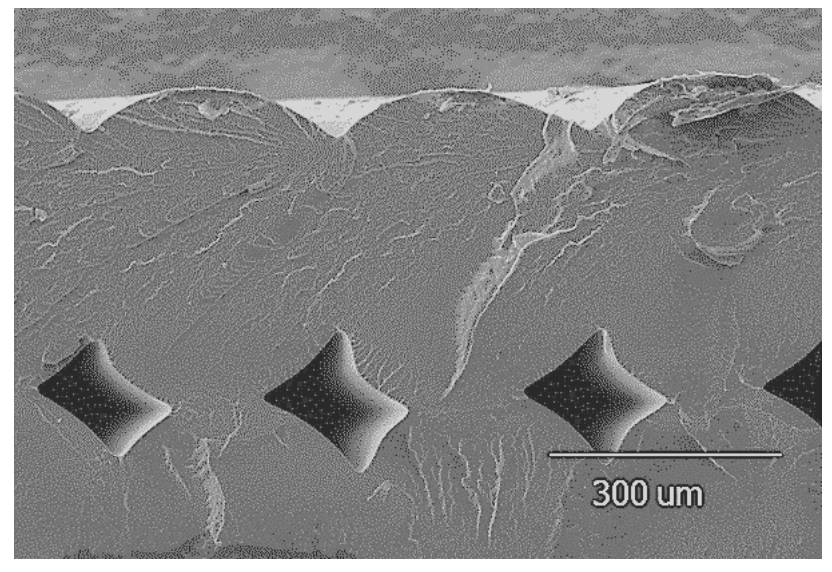

Figure 13. Micrograph of the cross-section of printed filaments obtained employing L13 process conditions. The corresponding value of the weld parameter, as defined in Figure 4, is $2 a_{w}=0.218 \pm 0.012 \mathrm{~mm}$. 


\subsection{Effect of process parameters on tear trouser adhesion of 3D printed PBSA}

We study the influence of process parameters on the tearing energy of both biopolymers: PBS and PBSA. However, due to the poor results obtained with PBS, only PBSA data are discussed here.

The corresponding tearing energies of samples printed at $190^{\circ} \mathrm{C}$ and submitted to different printing velocities and bed temperatures are presented in Tables 3 and 4.

Table 3: Tearing energy versus printing velocity of PBSA copolymer with a bed temperature of $25^{\circ} \mathrm{C}$ and a nozzle temperature of $190^{\circ} \mathrm{C}$.

\begin{tabular}{cccc}
\hline Condition & $\begin{array}{c}\text { Printing velocity } \\
(\mathrm{mm} / \mathrm{s})\end{array}$ & $\begin{array}{c}\text { Trouser energy } \\
(\mathrm{N} / \mathrm{mm})\end{array}$ & $\begin{array}{c}\text { Standard } \\
\text { deviation }\end{array}$ \\
\hline L11 & 2.0 & 27.7 & 0.7 \\
L12 & 3.5 & 26.3 & 0.2 \\
L13 & 5.0 & 29.5 & 1.0 \\
L14 & 6.5 & 26.5 & 0.1 \\
L15 & 9.5 & 27.8 & 0.2 \\
\hline
\end{tabular}

Table 4: Tearing energy versus bed temperature of PBSA copolymer with a nozzle temperature of $190^{\circ} \mathrm{C}$ and a printing velocity of $5 \mathrm{~mm} / \mathrm{s}$.

\begin{tabular}{cccc}
\hline Condition & $\begin{array}{c}\text { Bed temperature } \\
\left({ }^{\circ} \mathrm{C}\right)\end{array}$ & $\begin{array}{c}\text { Trouser energy } \\
(\mathrm{N} / \mathrm{mm})\end{array}$ & $\begin{array}{c}\text { Standard } \\
\text { deviation }\end{array}$ \\
\hline L13 & 25 & 29.5 & 0.6 \\
L23 & 30 & 13.3 & 0.2 \\
L33 & 35 & 11.3 & 0.3 \\
\hline
\end{tabular}

As can be seen in Table 3, the tearing energy values are independent of the printing velocities and slightly higher than those reported by Seppala et al. (38), (25 kN/m at the maximum, at $270^{\circ} \mathrm{C}$ ) for a commercial $\mathrm{ABS}$ with a bulk value of $36 \mathrm{kN} / \mathrm{m}$. 
According to the model of McIlroy and Olmsted (45), the entanglements number, $Z_{e}$, for typical printing materials should be in the range 20-30. Nevertheless, we found high tearing energies for our PBSA and for commercial ABS, which both have a lower entanglement number, i.e., $Z_{\mathrm{e}}=9$. Although tearing energies of widely used commercial PLAs have not been reported, good adhesion between layers is recognized. Typically the value of the entanglements number for PLA is around $Z_{e}=17$, which is also somewhat smaller than the range predicted by McIlroy and Olmsted (45).

As in the case of the ABS experimental results reported by Seppala et al. (36), in our results obtained with PBSA, we find no effect of the printing velocity on the tearing energies presented in Table 2, within the standard deviations of the measurements. The model of McIlroy and Olmsted (45) predicts that as printing velocity is increased, the effective number of entanglements should decrease, due to shear-induced disentanglement process, leading to a decrease in the tearing energy. We speculate that larger printing velocities are needed (not possible with our 3D printer with PBSA) to observe a significant decrease in tearing energy.

Concerning the effect of bed temperature on tearing energy, which is probably linked to the crystallization process, we have not found any paper reporting this effect. Indeed, according to our experimental results, the onset of crystallization takes place at $42^{\circ} \mathrm{C}$, whereas the selected bed temperatures are 25,30 , and $35^{\circ} \mathrm{C}$. The remarkable tearing energy value obtained at $\mathrm{T}=25^{\circ} \mathrm{C}(26 \mathrm{kN} / \mathrm{m})$ is reduced to less than half when bed temperatures are 30 and $35^{\circ} \mathrm{C}$. A tentative analysis of the effect of crystallization on the welding performance can be carried out by matching the corresponding bed temperatures with the DSC cooling scan of PBSA, as shown in Figure 15. It can be deduced from Figure 14, that much less crystallinity is developed when bed temperatures are $30^{\circ}$ and $35^{\circ} \mathrm{C}$, which probably causes considerably lower tearing energies, as compared with a bed temperature of $\mathrm{T}=25^{\circ} \mathrm{C}$ (Table 4). Indeed, the effect of solidification (via crystallization) on the welding performance of semi-crystalline polymers is an important issue in $3 \mathrm{D}$ printing that has not been considered in-depth, so far. 


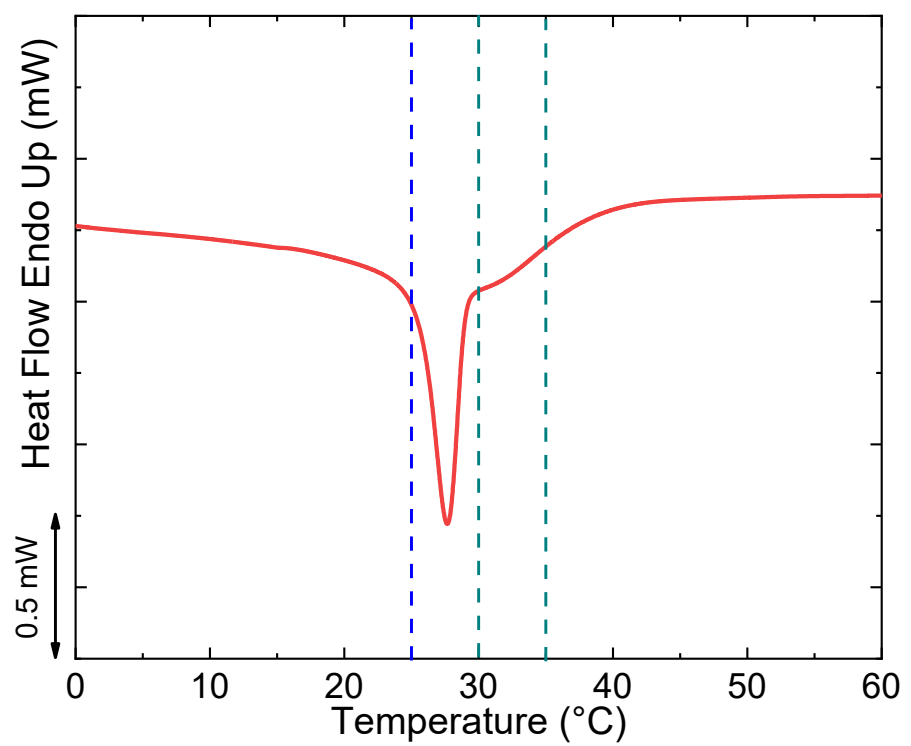

Figure 14: Cooling scan of PBSA, taken from Figure 3, matched with bed temperatures used in $3 \mathrm{D}$ printing under the conditions of Table 4 . The vertical lines correspond to the respective bed temperatures.

\section{Models printed by FFF}

Given the welding results reported in Section 3.2, the best printing conditions were selected to make 3D printed objects with PBSA filaments. These conditions are: Nozzle temperature $190^{\circ}$, bed temperature $25^{\circ} \mathrm{C}$ and a printing velocity of $5 \mathrm{~mm} / \mathrm{s}$. Several models, obtained with PBSA, are shown in Figure 15.

Printed parts obtained with PBS were not satisfactory, which is not unexpected, considering preliminary data reported by Ou-Yang et al. (34). As it is explained in Section 3.1, for PBS, the crystallization process extends between 80 and $40^{\circ} \mathrm{C}$ giving rise to the volume reduction observed in Figure 6, which leads to the significant dimensional instability noticed in Figure 16. In fact, the printing process takes place normally, but upon cooling on the bed (at $\mathrm{T}=25^{\circ} \mathrm{C}$ ), the sample suffers a rapid shrinkage. This troubling warpage phenomenon is not observed for PBSA, which has a crystallization temperature between 40 and $20^{\circ} \mathrm{C}$. The filaments of PBSA obtained, as indicated in Section 2.2, are easily printed at the conditions mentioned above, bringing about objects of excellent final appearance, like those shown in Figure 15. Interestingly enough, 3D printed PBSA copolymer bars display a 
ductile behavior with elongations at break similar to those obtained with injected specimens, as discussed in the next section.

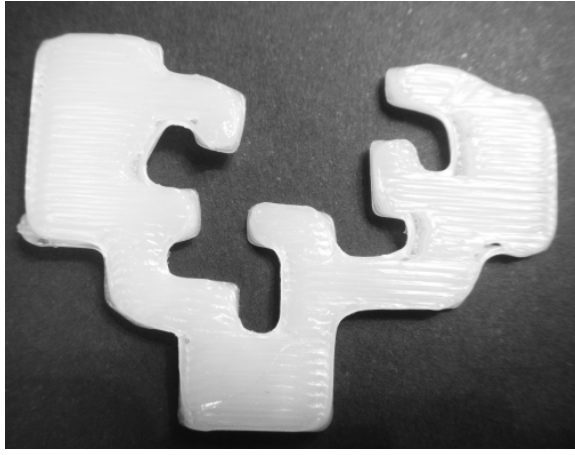

(a)

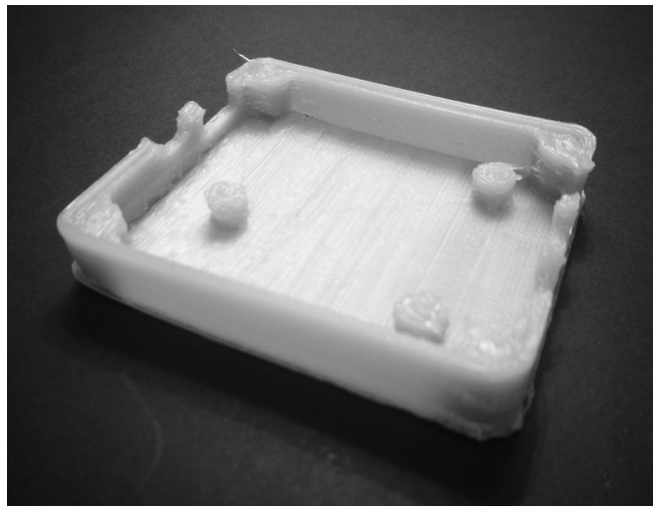

(c)

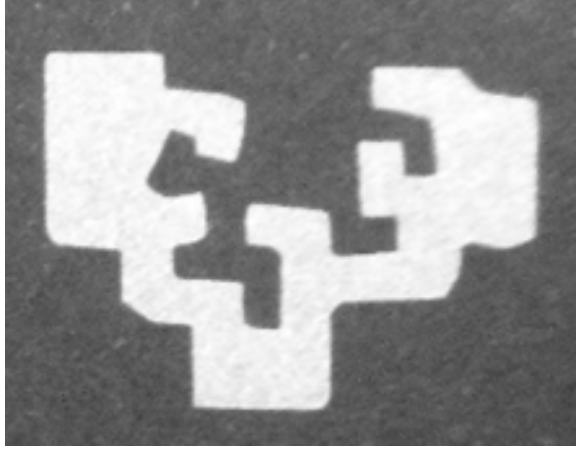

(b)

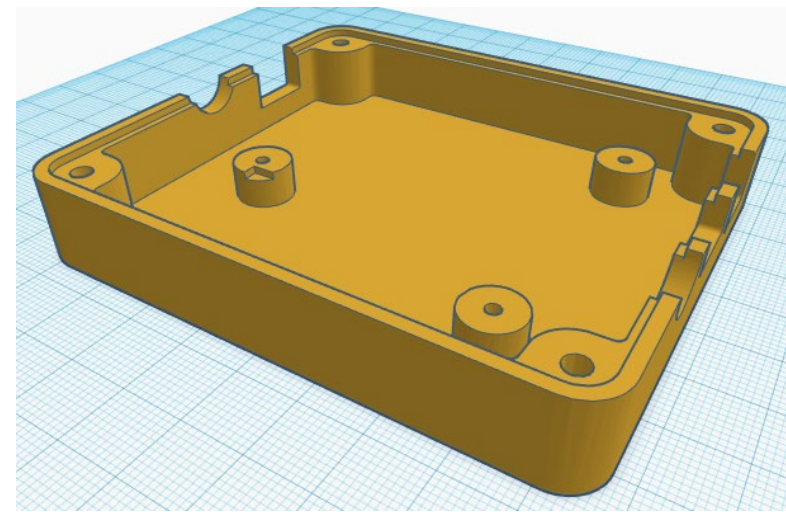

(d)

Figure 15: 3D printing parts with PBSA: (a) Logo of the UPV/EHU, (b) Original image of the logo of the UPV/EHU, (c) Printing Box with bosses and (d) Original image of the Box with bosses.

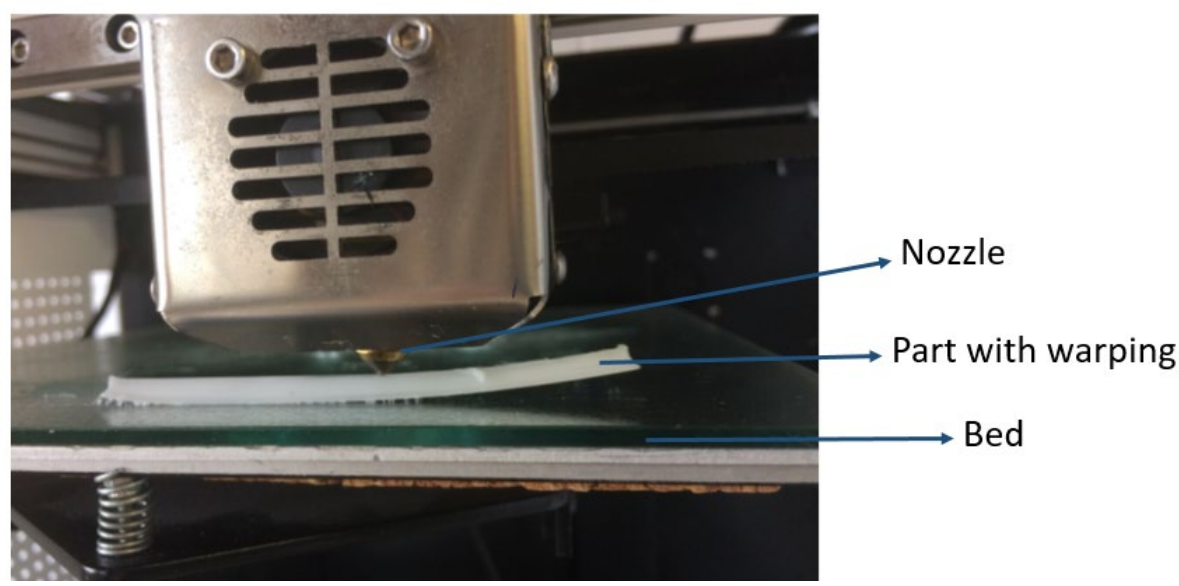

Figure 16: Warping of the PBS sample. 


\section{Mechanical properties}

Figure 17 shows typical stress-strain curves of 3D printed and injection-molded specimens. Photographs of a representative 3D printed specimen at different stages during the test are also shown in the figure. Both types of samples form stable necks that propagate up to approximately $200 \%$ elongation exhibiting remarkable ductility.

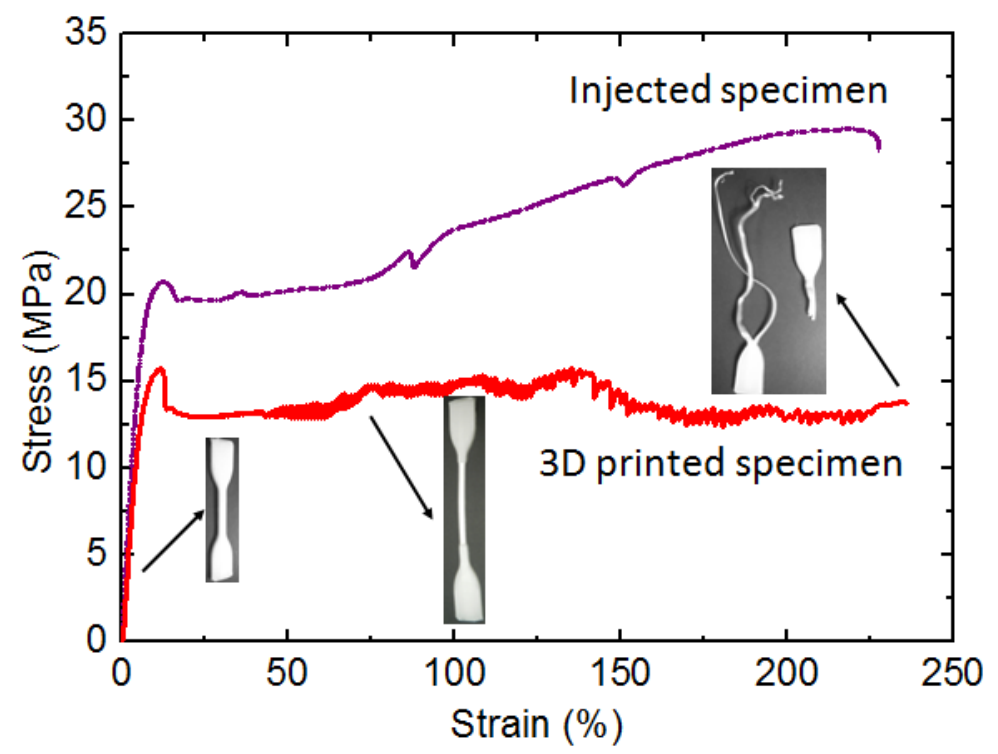

Figure 17: Tensile stress-strain curves of $3 \mathrm{D}$ printed and injected PBSA specimens.

Table 5 reports Young's modulus, tensile strength, and ductility (elongation at break) values obtained after testing five specimens. As can be seen, the average Young's modulus value of the $3 \mathrm{D}$ printed specimens is approximately $5 \%$ lower than that of the injectionmolded specimens, if the standard deviation values are taken into account. This difference is not significant.

The stress at yield decreases by $15 \%$ in $3 \mathrm{D}$ printed samples as compared to injection molded ones, while the stress at break experiences a $40 \%$ decrease. These results are due to the fact that injection-molded specimens experience strain hardening after neck propagation during the test, while 3D printed specimens do not. The 3D printed specimens also exhibit neck formation and propagation but hardly any strain hardening.

Interestingly, there is no difference in elongation at break between the 3D printed samples and the injection-molded specimens, when the standard deviations in the measurements are considered. 
Table 5: Mechanical properties of the 3D printed and injected PBSA.

\begin{tabular}{ccc}
\hline $\begin{array}{c}\text { MECHANICAL } \\
\text { PROPERTY }\end{array}$ & 3D PRINTED & INJECTED \\
& PBSA & PBSA \\
\hline Young's modulus (MPa) & $325 \pm 43$ & $380 \pm 5$ \\
Stress at yield (MPa) & $15.3 \pm 1.4$ & $21.0 \pm 0.4$ \\
Stress at break (MPa) & $15.9 \pm 3.3$ & $29.0 \pm 0.6$ \\
Elongation at break (\%) & $213 \pm 52$ & $230 \pm 9$ \\
\hline
\end{tabular}

When 3D printed specimens are compared with injection-molded samples, usually adverse effects are found. This relative reduction in tensile properties for 3D printed specimens has been reported for ABS (49), PC/ABS blends (50), and ABS/montmorillonite nanocomposites (51), with decreases similar or even higher than those observed in this work. Several factors have been pointed out as responsible for this behavior, some of them intrinsic to the $3 \mathrm{D}$ printing process and some others to the specific geometry used in each case. Among the formers, it is evident that injection molding results in higher material compaction, due to the high pressures employed and to the compensation of the material shrinkage during the holding stage. Moreover, cooling, and consequent crystallization, of the material takes place under different conditions, so structural aspects should also be considered. Among the geometric factors, the angle between filament alignment and tensile direction appears to be crucial, as well as the air gaps between individual filaments (see Figure 13).

As previously mentioned, the direction of the filament deposition during 3D printing coincides with that of the load during the tensile test, which is the most favorable geometry (49). Therefore, the decrease in yield strength could be related to the lower density of the 3D printed material and to the presence of air gaps between filaments (Figure 13), which reduce the effective section of the specimen.

As already pointed out above, the ductility of the 3D printed specimens is similar to that of the injection-molded ones, indicating a similar deformation ability of both materials. 
This is a very positive behavior, and points to an excellent adhesion between individual filaments, even at high strain values.

\section{Conclusions}

We have shown that the thermal and rheological features of polybutylene succinate (PBS) and poly(butylene succinate-ran-adipate) (PBSA) are related to the performance of both samples in 3D printing by fused filament fabrication (FFF) method. For both polymers, excellent filaments are obtained, concluding that this is compatible with the rheological results.

The good welding of the printed layers is demonstrated using ad hoc tearing experiments. For the first time, the effect of bed temperature on welding energy is reported. Tearing energy values agree with those reported in the literature for ABS. According to our results, the polymer melts should not necessarily have high entanglements densities to bring about excellent interlayer adhesion or welding.

A troubling warpage phenomenon is observed for PBS, but PBSA shows excellent feasibility for FFF, bringing about dimensionally stable models with high elongations, opening new processing routes for ductile biodegradable polymers.

\section{Acknowledgment}

This work has received funding from the European Union's Horizon 2020 research and innovation program under the Marie Sklodowska-Curie grant agreement No 778092, from MINECO, project: MAT2017-83014-C2-1-P and from the Basque Government through grant IT1309-19.

\section{References}

1. T. Ngo, A. Kashni, G. Imbalzano, K. Nguyen, D. Hui, Additive manufacturing (3d printing): A review of materials, methods, applications and challenge, Composites Part B. Engineering. 143(15) (2018), 172-196. https://doi.org/10.1016/j.compositesb.2018.02.012

2. B. Redwood, F. Schöffer, B. Garret, The 3D Printing Handbook: Technologies, design and applications”, 3D Hubs, New York, 2017. 
3. J.V. Eckera, I. Burzica, A. Haidera, S. Hildb, H. Rennhoferc, Improving the impact strength of PLA and its blends with PHA in fused layer modeling, Polymer Testing. 78 (September) (2019), 105929. https://doi.org/10.1016/j.polymertesting.2019.105929.

4. C. Wendt, M. Batista, E. Moreno, A. Valerga, S. Fernández-Vidal, O. Droste, M. Marcos, Preliminary design and analysis of tensile test samples developed by Additive $\begin{array}{llll}\text { Manufacturing, } & \text { Procedia } & \text { Eng. } & 132\end{array}$ (2015), 132-139. https://doi.org/10.1016/j.proeng.2015.12.489.

5. Y. Song, Y. Li, W. Song, K. Yee, K. Lee, V. Tagarielli, Measurements of the mechanical response of unidirectional 3D-printed PLA, Mater. Des. 123 (2017), 154-164. https://doi.org/10.1016/j.matdes.2017.03.051.

6. T. Yao, Z. Deng, K. Zhang, S. Li, A method to predict the ultimate tensile strength of 3D printing polylactic acid (PLA) materials with different printing orientations, Composites Part B: Engineering. 63 (2019), 393-402. https://doi.org/10.1016/j.compositesb.2019.01.025. 7. E. Bartolomé, B. Bozzo, P. Sevilla, O. Martínez-Pasarell, T. Puig, X. Granados, ABS 3D printed solutions for cryogenic applications, Cryogenics. 82 (2017), 30-37, https://doi.org/10.1016/j.cryogenics.2017.01.005.

8. C. Ziemian, M. Sharma, S. Ziemian, Anisotropic mechanical properties of ABS parts fabricated by fused deposition modelling, Mechanical Engineering. Edited by Dr. Murat Gokcek, InTech. DOI: 10.5772/34233

9. B. Rankouhi, S. Javadpour, F. Delfanian, T .J. Letcher, Failure analysis and mechanical characterization of 3D printed ABS with respect to layer thickness and orientation, Fail. Anal. Prev. 16 (3) (2016), 467-481. DOI: 10.1007/s11668-016-0113-2.

10. D. H. Ahn, M. Montero, D. Roundy, P. Wrigh, Anisotropic material properties of fused deposition modelling ABS, Rapid Prototyp. $8 \quad$ (4) (2002), 248. https://doi.org/10.1108/13552540210441166

11. K. Kim, J. Park, J. Suh, M. Kim, I. Park, 3D printing of multiaxial force sensors using carbon nanotube (CNT)/thermoplastic polyurethane (TPU) filaments, Sensors and Actuators A: Physical. 263 (August) (2017), 493-500. https://doi.org/10.1016/j.sna.2017.07.020.

12. D. Rigotti, A. Dorigato, A.Pegoretti, 3D printable thermoplastic polyurethane blends with thermal energy storage/release capabilities, Materials Today Communications. 15 (June) (2018), 228-235. https://doi.org/10.1016/j.mtcomm.2018.03.009. 
13. K. Rahman, T. Letcher, T. Reese, Mechanical properties of additively manufactured PEEK components using fused filament fabrication, (IMECE) Proceedings of the ASME 2015 International Mechanical Engineering Congress and Exposition, Houston, Texas (2015). https://doi.org/10.1115/IMECE2015-52209.

14. B. Hu, X. Duan, Z. Xing, Z. Xu, B. Shan, Improved design of fused deposition modeling equipment for 3D printing of high-performance PEEK parts, Mechanics of Materials. 137 (October), (2019). https://doi.org/10.1016/j.mechmat.2019.103139.

15. C. Yang, X. Tian, D. Li, Y. Cao, Ch. Shi, Influence of thermal processing conditions in 3D printing on the crystallinity and mechanical properties of PEEK material, Journal of Materials Processing Technology. $248 \quad$ (October) (2017), 1-7, https://doi.org/10.1016/j.jmatprotec.2017.04.027.

16. M. J. Reich, A.L.Woern, N.G. Tanikella, J.M. Pearce, Mechanical Properties and Applications of Recycled Polycarbonate Particle Material Extrusion-Based Additive

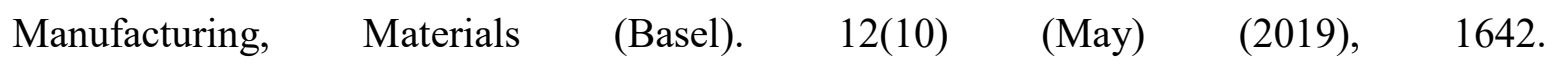
https://doi.org/10.3390/ma12101642.

17. A. S. Alaboodi, S. Sivasankaran, Experimental design and investigation on the mechanical behavior of novel 3D printed biocompatibility polycarbonate scaffolds for medical applications, Journal of Manufacturing Processes. 35 (October) (2018), 479-491. https://doi.org/10.1016/j.jmapro.2018.08.035.

18. M. Spoerk, C. Holzer, J. Gonzalez, J. Gutierrez, Material extrusion-based additive manufacturing of polypropylene: A review on how to improve dimensional inaccuracy and warpage, Journal of Applied Polymer Science. REVIEW (2019), 1-16. https://doi.org/10.1002/app.48545 DOI: 10.1002/app.48545.

19. N.E. Zandera, M. Gillana, Z. Burckhard, F. Gardeac, Recycled polypropylene blends as novel 3D printing materials, Additive Manufacturing. 25 (January) (2019), 122-130. https://doi.org/10.1016/j.addma.2018.11.009

20. W. Wu, W. Ye, P. Geng, Y. Wang, G. Li, X. Hu, J. Zhao, 3D printing of thermoplastic PI and interlayer bonding evaluation, Materials Letters. 229 (2018), 206-209. https://doi.org/10.1016/j.matlet.2018.07.020.

21. R.A. Pérez-Camargo, B. Fernández-d'Arlas, D. Cavallo, T. Debuissy, E. Pollet, L. Avérous, A.J. Müller, Tailoring the Structure, Morphology, and Crystallization of 
Isodimorphic Poly (butylene succinate-ran-butylene adipate) Random Copolymers by Changing Composition and Thermal History, Macromolecules. 50 (2017), 597-608 (January). https://doi.org/10.1021/acs.macromol.6b02457.

22. R.A. Pérez-Camargo, I. Arandia, M. Safari, D. Cavallo, N. Lotti, M. Soccio, A.J. Müller, Crystallization of isodimorphic aliphatic random copolyesters: Pseudo-eutectic behavior and double-crystalline materials, European Polymer Journal. 101 (April) (2018), 233-247. https://doi.org/10.1016/j.eurpolymj.2018.02.037.

23. D.K. Song, Y.K. Sung, Synthesis and characterization of biodegradable poly (1, 4butanediol succionate), J. Appl. Polym. Sci. 56(11) (1995), 1381-1395. https://doi.org/10.1002/app.1995.070561102.

24. V. Ojijo, S.S. Ray, (2012) "Poly (Butylene Succinate) and Poly [(Butylene Succinate)co-Adipate] Nanocomposites", in: Avérous L., Pollet E. (eds) Environmental Silicate NanoBiocomposites. Green Energy and Technology. Springer, London.

25. M.S. Nikolic, J. Djonlagic, Synthesis and characterization of biodegradable poly (butylene succinate-co-butylene adipate), Polym Degrad Stabil. 74 (2001), 263-270. https://doi.org/10.1016/S0141-3910(01)00156-2.

26. B.D. Ahn, S.H. Kim, Y.H. Kim, J.S. Yang, Synthesis and characterization of the biodegradable copolymers from succinic acid and adipic acid with 1,4-butanediol, J Appl Polym Sci. 82 (2001), 2808-2826. https://doi.org/10.1002/app.2135.

27. C. Zhu, Z. Zhang, Q. Liu, Z. Wang, J.J. Jin, Synthesis and biodegradation of aliphatic polyesters from dicarboxylic acids and diols, Appl Polym Sci. 90 (2003), 982-990. https://doi.org/10.1002/app.12722.

28. M. Fabbria, M. Giglib, R. Gamberinia, N. Lotti, M. Gazzanoc, B. Riminia, A. Munarib, Hydro-lysable PBS-based poly(ester urethane)s thermoplastic elastomers, Polym Degr Stab. 108 (2014), 223 - 231. https://doi.org/10.1016/j.polymdegradstab.2014.03.033.

29. V. Siracusa, N. Lotti, A. Munari, M. Dalla Rosa, Poly(butylene succinate) and poly(butylene succionate-co-adipate) for food packaging applications: Gas barrier properties after stressed treatments, Polymer Degradation and Stability. 115 (2015), 35-45. https://doi.org/10.1016/j.polymdegradstab.2015.04.026.

30. M. Puchalski, G. Szparaga, T. Biela, A. Gutowska, S. Sztajnowski, L. Kruciñska, Molecular and Supramolecular changes on Polybutylene succinate (PBS) and Polybutylene 
succinate adipate (PBSA) copolymer during degradation in various environmental conditions Polymers. 10 (3) (2018), 251. https://doi.org/10.3390/polym10030251.

31. H. Ishikawa, S. Omori, Y. Ohki, Dielectric properties of Polybutylene succinate and Polybutylene succinate adipate, 2007 International conference on solid dielectrics, International Conference on Solid Dielectrics Winchester UK, Jul 8-134, 2007. DOI: 10.1109/ICSD.2007.4290893.

32. S. Mallardo, V. De Vito, M. Malinconico, M.G. Volpe, G. Santagata, M.L. Di Lorenzo. 2018, "Biodegradable Poly(Butylene Succinate)-Based Composites for Food Packaging”. In: Cocca M., Di Pace E., Errico M., Gentile G., Montarsolo A., Mossotti R. (eds) Proceedings of the International Conference on Microplastic Pollution in the Mediterranean Sea. Springer Water. Springer, Cham. DOI: 10.1007/978-3-319-71279-6_27.

33. S. Su, R. Kopitzky, S. Tolga, S. Kabasci, Polylactide (PLA) and Its Blends with Poly(butylene succinate) (PBS): A Brief Review, Polymers (Basel). 11(7) (July) (2019), 1193. https://doi.org/10.3390/polym11071193.

34. Q. Ou-Yang, B. Guo, J. Xu, Preparation and Characterization of Poly(butylene succinate)/Polylactide Blends for Fused Deposition Modeling 3D Printing, ACS Omega. 3 (10) (2018), 14309-14317. https://doi.org/10.1021/acsomega.8b02549.

35. J. Dizon, A.H. EsperaJr, Q. Chen, R.C. Advincula, Mechanical characterization of 3Dprinted polymers, Additive manufacturing. 20 (March) (2018), 44-67. https://doi.org/10.1016/j.addma.2017.12.002.

36. A. Foster, A.; 2015, "Materials testing standards for additive manufacturing of polymer materials: state of the art and standards applicability", NIST 8059, EEUU. .

37. C. Davis, K. Hillgartner, S. Hoon Han, J. Seppala, Mechanical strength of welding zones produced by polymer extrusion additive manufacturing, Additive manufacturing. 16 (2017), 162-166. https://doi.org/10.1016/j.addma.2017.06.006.

38. J. Seppala, S. Hoon Han, K. Hillgartner, C. Davis, K. Migler, Weld formation during material extrusion additive manufacturing, Soft Matter. 13 (2017), 6761-6769. DOI: 10.1039/C7SM00950J.

39. S. Charlon, L. Delbreilh, E. Dargent, N. Follaina, J. Soulestin, S. Maraisa, Influence of crystallinity on the dielectric relaxations of poly(butylene succinate) and poly[(butylene 
succinate)-co-(butylene adipate), European Polymer Journal. 84 (November) (2016), 366376. https://doi.org/10.1016/j.eurpolymj.2016.09.045

40. I. Arandia, N. Zaldua, J. Maiz, R. Pérez-Camargo, A. Mugica, M. Zubitur, R. Mincheva, P. Dubois, A.J. Müller, Tailoring the isothermal crystallization kinetics of isodimorphic poly (butylene succinate-ran-butylene azelate) random copolymers by changing composition, Polymer. 121863 (Noviembre) (2019). https://doi.org/10.1016/j.polymer.2019.121863.

41. J. Ferry. "Viscoelastic Properties of Polymers", Wiley, EEUU, 1980.

42. W.P. Cox, E.H. Merz, Correlation of dynamic and steady flow viscosities, Journal of Polymer Science. 28 (2958), 619-622. https://doi.org/10.1002/pol.1958.1202811812

43. Standard ASTM D1938 - 19, Standard Test Method for Tear-Propagation Resistance (Trouser Tear) of Plastic Film and Thin Sheeting by a Single-Tear Method, EEUU.

44. Standard ASTM D638 - 14, Standard Test Method for Tensile Properties of Plastics, EEUU.

45. C. McIlroy, P.D. Olmsted, Disentanglement effects on welding behaviour of polymer melts during the fused-filament-fabrication method for additive manufacturing, Polymer. 123 (11) (2017), 376-391. https://doi.org/10.1016/j.polymer.2017.06.051.

46. C. Liu, J. He, E. Van Ruymbeke, R. Keunings, C. Bailly, Evaluation of different methods for the determination of the plateau modulus and the entanglement molecular weight, Polymer. 47 (2006), 4461-4479. https://doi.org/10.1016/j.polymer.2006.04.054.

47. M.R. Nobile, F. Cocchini. Evaluation of molecular weight distribution from dynamic moduli, Rheologica Acta. 40 (2) (2001), 111-119. DOI:10.1007/s003970000141.

48. I. Palade, H.J. Lehermeier, J.R.Dorgan, Melt Rheology of High 1-Content Poly (lactic acid), Macromolecules. 34 (5) (2001), 1384-1390. https://doi.org/10.1021/ma001173b.

49. M. Dawoud, I. Taha, S. Ebeid, Mechanical behaviour of ABS: An experimental study using FDM and injection moulding techniques, Journal of Manufacturing Processes. 21 (2016), 39-45. https://doi.org/10.1016/j.jmapro.2015.11.002.

50. L. Behalek, J. Safka, M. Seidi, J. Habr, J. Bobek, Fused Deposition modelling vs. Injection moulding: Influence of fiber orientation and layer tchickness on the mechanical properties, MM Science Journal. December (2018), 2722-2726. DOI: 10.17973/MMSJ.2018_12_2018117. 
51. Z. Weng, J. Wang, T.Senthil, L. Wu, Mechanical and thermal properties of $\mathrm{ABS} /$ montmorillonite nanocomposites for fused deposition modeling 3D printing, Materials \& Design. 102 (July) (2016), 276-283. https://doi.org/10.1016/j.matdes.2016.04.045. 